\title{
APLICACIÓN DE CORRELACIÓN CANÓNICA PARA LA DETECCIÓN DE LA INFLUENCIA DE LA PRÁCTICA RELIGIOSA EN LA INTEGRACIÓN POLÍTICA DE LOS INMIGRANTES*
}

\section{APPLICATION OF THE CANONICAL CORRELATION FOR THE DETECTION OF THE INFLUENCE OF RELIGIOSITY IN THE POLITICAL INTEGRATION OF MIGRANTS}

GUILLERMo BoscÁN CARRASQUERO Universidad Pontificia de Salamanca PABLO NICOLÁs BIDERBOST Universidad Pontificia Comillas

\section{RESUMEN}

El nivel de religiosidad ha sido identificado como uno de los factores que promueven (o contraen) las diferentes competencias cívicas que, a su vez, son tomadas como indicadores de integración política de los inmigrantes en las sociedades de acogida. En el presente artículo, se presentan los resultados de una investigación que, entre otras variables, ha explorado cómo la práctica religiosa contribuye al desarrollo de distintas actitudes políticas entre adolescentes de origen inmigrante que asisten a escuelas secundarios y/o bachilleratos en once ciudades españolas. Los datos recogidos son analizados

* Ambos autores han contribuido en igualdad de condiciones y de carga de trabajo para la preparación de este artículo. Los resultados de esta investigación son una derivación de un proyecto financiado por la Junta de Castilla y León (SA010B08/ORDEN EDU/1160/2008). 
mediante la técnica de estadística multivariante denominada Análisis de Correlación Canónica.

Palabras clave: religiosidad, integración política, competencias cívicas, inmigración, adolescencia.

\section{ABSTRACT}

The level of religiosity has been identified as one of the factors promoting (or diminishing) the different civic competencies. The latter are, at the same time, indicators of the level of political integration of the migrants in the host societies. In this article, we share the results of a research where we explored the influence of the religious practices on the development of political attitudes among teenagers with migrant background attending secondary and high schools in eleven Spanish cities. Data collected is statistically analysed making use of Canonical Correlations.

Keywords: religiosity, political integration, civic competencies, immigration, adolescence.

\section{INTRODUCCIÓN}

España se ha convertido recientemente en un estado receptor neto de inmigrantes. Ello ha generado, en todas las disciplinas científicas, una miríada de estudios que tienen por objeto detectar cómo los recién llegados se integran en las diferentes dimensiones de la sociedad de acogida. La integración política es una de las esferas que ha sido explorada tanto en relación con población adulta (Morales, Anduiza, Rodríguez y San Martín, 2008; Morales y Morariu, 2011, González-Ferrer, 2011; Bermúdez, 2011) como en vinculación a inmigrantes adolescentes (Biderbost, 2010; 2014; Biderbost y Boscán, 2019).

Distintas variables han sido sindicadas como causantes de los niveles de integración política de los inmigrantes en sociedades de acogida. Existe una larga tradición de estudios anglosajones que incluye entre las mismas a la religiosidad. Una profusa evidencia empírica respalda que los sujetos con una práctica religiosa más profunda suelen poseer un mayor desarrollo de sus competencias cívicas (Djupe y Grant, 2001; Jones-Correa y Leal, 2001). Este es un artículo que, para población adolescente de origen extranjero, explora la relación que existe entre la religiosidad como variable independiente y la integración política como variable dependiente. Este documento es un producto de una investigación que se ejecutó en 11 ciudades españolas y que tenía por objeto 
observar si existían brechas de tipo cívico-político entre nativos e inmigrantes en las escuelas secundarias y bachilleratos públicos.

La estructura del texto es la que se detalla a continuación. En un primer lugar, se presenta teóricamente el concepto de integración política y se describen a las competencias cívicas como indicadores del mismo. En un segundo momento, se comenta cómo, tanto conceptual como empíricamente, se han previsto lazos entre la práctica religiosa y la integración política. En un tercer apartado, se detalla cómo fueron operacionalizadas variables dependientes e independientes. A posteriori, se reseñan los datos, métodos e hipótesis que guiaron la exploración de la ligazón entre las dos variables. Luego, se introducen y discuten los hallazgos. Finalmente, se presentan unas conclusiones derivadas de los resultados.

\section{LA INTEGRACIÓN POLÍTICA DE LOS INMIGRANTES Y EL USO DE LAS COMPETENCIAS CÍVICAS}

La literatura politológica producida en Estados Unidos y Europa que coloca a los inmigrantes como objeto de estudio ha crecido profusamente en las últimas décadas. El propósito que subyace a estos trabajos es reflexionar sobre cuáles son los niveles de integración política de los newcomers en las sociedades receptoras $^{1}$ (Hammar, 1989; Rex y Singh, 2003; Jacobs y Tillie, 2004; Portes et al. 2008). En otras palabras, estas investigaciones intentan detectar escenarios actuales o potenciales de marginación o exclusión cívica (Biderbost, 2010). La motivación para la ejecución de estos estudios difiere entre Estados Unidos y Europa. Laura Morales (2011) recuerda que la perspectiva prevaleciente en la academia anglosajona privilegia la indagación sobre los factores individuales y del entorno cercano que influyen en la integración política de los sujetos.

En tanto, en los claustros europeos, el enfoque se ha centrado en detectar qué modelos de ciudadanía han favorecido la integración política de la población extranjera en las sociedades nacionales receptoras. La tradición europea también ha estudiado, tomando prestado elementos de la teoría de los movimientos sociales, cómo las capacidades organizativas y el capital social de las agrupaciones inmigrantes inciden en su integración política. Esta situación de "mesas separadas" ha comenzado a superarse gracias a los recientes esfuerzos

1 En los últimos años, en el marco de la literatura vinculada a transnacionalismo, se han multiplicados los estudios que indagan sobre la situación política de los inmigrantes en relación con sus sociedades de origen. En este apartado, sin embargo, sólo se procederá a describir las investigaciones que vinculan, en el plano político, a los inmigrantes con las sociedades de destino. El trabajo de Biderbost, Bolzman y Boscán (2019) constituye un recurso interesante para todos aquéllos interesados en explorar la relación existente entre las sociedades de origen y el comportamiento político de los emigrantes. 
de investigadores que intentan unir la visión "micro" estadounidense con la mirada "macro" europea.

Otro aspecto en esta área de estudios que tampoco refleja uniformidad entre los investigadores occidentales es el vinculado a la utilización y definición de conceptos que refieran/describan la "situación política" que presentan los inmigrantes en las sociedades de destino. En ello, ha influido el que la producción científica sobre estos temas procede de diferentes disciplinas (Ciencia Política, Sociología Política y Psicología Política). Mientras un grupo importante de científicos sociales opta por el uso del concepto de integración política, otros estudiosos prefieren la aplicación de las expresiones asimilación política o incorporación política. Morales (2011) advierte sobre el riesgo que implica el elegir el concepto de asimilación al referirse a la dimensión política de la migración. El mismo, menos problemático cuando se estudia la convergencia económica, laboral o educativa entre foráneos y autóctonos, puede encontrarse embebido de etnocentrismo cuando se analizan rasgos políticos.

En tanto, el concepto de incorporación política, en la perspectiva de esta autora, describe el proceso por el cual un individuo (o un colectivo de individuos) de origen inmigrante se incluye políticamente en la sociedad en la que habitan. El concepto de integración política, paralelamente, describe cómo se encuentra en un momento dado en el tiempo la inclusión política de un individuo (o un colectivo) inmigrante en la sociedad receptora. La incorporación y la integración son dos caras de una misma moneda conceptual: la inclusión politica. La última expresión refiere a la ausencia de exclusión o marginación de los procesos políticos en los que se procede a la toma de decisiones.

Los autores de estas líneas también creen que resulta más apropiada la utilización del concepto de integración política por diferentes motivos. En primer lugar, el uso en Ciencia Política de la expresión "integración” engarza mejor con su aplicación por parte de otras disciplinas científicas para referir a la situación que presentan los inmigrantes en diferentes dimensiones de la vida social (sistema educativo, mercado de trabajo, sistema sanitario, etc.). En tal sentido, su uso permite ver cuán similares/diferentes son los inmigrantes y autóctonos entre sí de cara a evitar situaciones de marginación política. En segundo lugar, existen registros del uso de la expresión para referirse a los procesos migratorios tan tempranamente como en el decenio de 1950 (Glazer, 1956) ${ }^{2}$. En tercer lugar, la

2 Nathan Glazer, en su obra "The integration of American Immigrants" (1956), propone un concepto multidimensional de integración en el que, junto a elementos sociales y culturales, la situación política de los inmigrantes en la sociedad de acogida juega un rol preponderante. Tiempo después, en 1961, Robert Dahl en su trabajo "Who governs?: democracy and power in an American city" hace uso también 
expresión, en comparación a las otras ya referidas, tiene menos carga "valorativa" (o connotación negativa). Finalmente, el concepto refleja mejor lo que se ha intentado medir y analizar en la investigación que se está comentando en este artículo (la distancia entre adolescentes inmigrantes y autóctonos en materia de competencias cívicas en un momento dado del tiempo)

Con independencia de la expresión utilizada, lo que esta tradición de estudios persigue es, primeramente, generar información sobre los vínculos de los individuos o colectivos inmigrantes con el sistema político anfitrión (Bloemraad, 2006; O’Neill, Gidengil y Young, 2012). A tales fines, se procede a la medición de determinados rasgos cívicos o políticos que ofician de indicadores de la integración política. En estos estudios, se pretende, a su vez, explicar cuáles son los factores (individuales o ambientales-contextuales) que propician la posesión de determinados niveles de integración política. Con tal propósito, se realizan interesantes comparaciones entre poblaciones inmigrante y autóctona y entre diferentes colectivos inmigrantes. En consecuencia, los niveles de integración política son usualmente de tipo relativo, es decir, de un colectivo en relación con otro.

Cabe agregar que, en los estudios sobre integración política, se mantiene siempre latente la idea de que la resocialización política que apareja toda experiencia migratoria configura perfiles cívico-políticos diversos. Por ese motivo, este grupo de investigaciones descansa, implícita o explícitamente, sobre la tradición de estudios acerca de la socialización política de los sujetos ${ }^{3}$.

Entre los investigadores que han buscado encontrar indicadores de la integración política de los inmigrantes en las sociedades anglosajonas, se encuentran aquellos que han indagado sobre las competencias cívicas que presentan los individuos (Niemi y Chapman 1998; Yates y Younnis 1999). Estos activos hacen referencia a atributos cuya posesión se considera valiosa para evitar escenarios de desigualdad política, es decir, situaciones en las que el terreno de lo político quede en manos de ciertos sectores sociales en detrimento de otros excluidos cívicamente.

En estas investigaciones, se supone que dicha exclusión es factual y puede manifestarse con independencia de las libertades formales que puedan ser reconocidas, a todos los ciudadanos, por un ordenamiento jurídico puntual. Las competencias cívicas que suelen ser exploradas en estos estudios son variopintas. El

de la expresión "integración política" de los inmigrantes al describir cómo las organizaciones étnicas la propician.

3 En ocasiones, existe una mención expresa del interés de los investigadores por detectar cuál ha sido la naturaleza de la socialización política de los inmigrantes en las sociedades tanto de origen como de acogida. En otros casos, esta intención, aunque no central, es de tipo colateral y ello se percibe cuando se analizan pormenorizadamente los diseños de investigación adoptados. 
conocimiento político, la atención política, la participación política, la eficacia política y la tolerancia política se encuentran entre las mismas (Biderbost, 2014; Torney-Purta, Barber y Winkelfeld, 2007).

\section{LA RELIGIÓN COMO FACTOR MOTIVANTE DE LA INTEGRACIÓN POLÍTICA}

En la tradición anglosajona de estudios sobre el perfil cívico de los individuos, la religión (entendida como membresía a un grupo religioso), la religiosidad y la práctica religiosa ${ }^{4}$ han sido abordadas como variables independientes. Diferentes son las hipótesis que se encuentran detrás de este abordaje. Una de ellas es la que sugiere que la dimensión comunitaria de las dinámicas eclesiales (con independencia del credo que se profese) entrena para el diálogo político, la resolución compartida de problemas también compartidos y el ejercicio de una ciudadanía activa. Este proceso adquiere un tenor incluso más relevante cuando se habla de sociedades de acogida ya que las iglesias hacen las veces de terreno en el que los inmigrantes ensayan conductas cívicas que luego pueden también desempeñar en el sistema político. Otra de ellas es la que entiende que el seguimiento en comunidad de normas religiosas impregna a los creyentes de valores que, a posteriori, quieren ver defendidos en la vida pública. Un tercer supuesto es aplicable de manera exclusiva a los feligreses de origen extranjero. Es el que recuerda que los espacios de culto no suelen discriminar por origen nacional y, en ellos, se va produciendo un mestizaje cívico-cultural que facilita los procesos de inserción en el entramado político de las sociedades de acogida.

Numerosa es la evidencia empírica que respalda estas hipótesis ${ }^{5}$. Miller y Wattengerg (1984) han descubierto que la intensidad en la práctica religiosa se encuentra vinculada a la adhesión a determinadas ideas políticas, a la probabilidad de votar en elecciones y al entusiasmo expuesto por persuadir a otros en relación con cómo deben sufragar. En su estudio, existía un claro efecto de la religiosidad en la participación política de los creyentes ${ }^{6}$. Semejantes hallazgos

4 Religiosidad y práctica religiosa en estos estudios han sido entendidas generalmente como sinónimos. Por ellas, se investiga cuán central resulta la religión en la vida de las personas. Ha sido regularmente medida a través de preguntas que interrogan sobre los niveles de adhesión del entrevistado a los mandatos de determinado culto.

5 Los efectos cívicos de la religiosidad son teóricamente previstos con independencia del género de los feligreses. Sin embargo, una aportación contemporánea rescata que la práctica religiosa es, fundamentalmente, un predictor del protagonismo político de las mujeres en la mediana edad (Turska-Kawa, 2018).

6 Como es posible observar, el tipo de participación política en la que detectaron estos autores esta influencia era el voto (participación en elecciones). Sin embargo, los efectos eran prácticamente 
fueron derivados de la investigación ejecutada por Guth y Green (1990). Las personas que se autodefinían como religiosas, con independencia de su ideología, se presentaban más activas en materia de distribución de literatura política, asistencia a reuniones de corte político o militancia a nivel local.

Más recientemente, Djupe y Grant (2001) también han concluido que la incursión frecuente en actividades religiosas o cultuales, bajo determinadas coordenadas, estimula la participación política de los individuos. Jones-Correa y Leal (2001) encontraron evidencia empírica que soporta la idea de que la asistencia frecuente a celebraciones religiosas se encuentra positivamente asociada a diferentes maneras de participar políticamente con independencia del origen étnico de los sujetos. A su vez, Kelly y Morgan (2005) han hallado que el nivel de compromiso religioso, en combinación con la fe profesada, direccionan en determinados sentidos la actuación política de los individuos.

Estos hallazgos se observan también en estudios que, como foco, han incorporado población de origen inmigrante. Dana, Barretto y Oskooii (2011), en su investigación sobre el rol desempeñado por la asistencia al culto islámico, han encontrado evidencia empírica que respalda que esta práctica religiosa, al igual que sucede con las iglesias judía, protestante y católica, contribuye a generar un proceso de reformulación identitaria que acerca políticamente a los recién llegados con la sociedad de acogida. La práctica religiosa también estimularía el seguimiento sobre noticias políticas en medios de comunicación, indicador de la competencia denominada atención política. En el mismo sentido, Just, Sandovici y Listhaug (2013) han concluido que la religiosidad provoca mayores niveles de participación política no institucionalizada, es decir, aquella que tiene lugar cuando se procede a la firma de peticiones, la participación en manifestaciones y la realización de boicot a productos. Así mismo, McAndrew y Voas (2014) han identificado que la centralidad de la religión en la vida de sujetos involucrados en una experiencia migratoria conduce a una performance más elevada en materia de participación política y social ${ }^{7}$.

Sin embargo, la evidencia empírica indica que no todas las competencias cívicas parecen ser estimuladas por la práctica religiosa. En este marco, los vínculos entre, por un lado, la adscripción religiosa y, por el otro, el nivel de religiosidad (en sus diferentes dimensiones: pensamiento doctrinal, pertenencia a un culto y compromiso en el comportamiento) y el grado de tolerancia política

inexistentes sobre otros resortes de participación tales como la asistencia a mítines, el trabajo en campañas electorales o la donación de dinero por motivos políticos.

7 La correlación de la religiosidad en su estudio también es positiva, aunque no significativa desde el punto de vista estadístico, con la expresión de la posesión de confianza en los congéneres mediante el uso de la Generalized Trust Question (GTQ). 
expresado por los sujetos han sido explorados en la literatura. En estas indagaciones, se ha hallado que, a mayor implicación religiosa, puede emerger un menor nivel de tolerancia política (Niemi y Chapman, 1998; Eisenstein, 2006).

\section{OPERACIONALIZACIÓN DE VARIABLES DEPENDIENTES E INDE- PENDIENTES}

La integración política es conceptualmente definida como la descripción estática (valores presentados en un momento dado del tiempo) de las actitudes y comportamientos que un individuo (inmigrante o nativo) asume con relación al sistema político de la sociedad en la que habita. La medición de la integración política puede ser considerada como una fotografía que permite conocer las características de un momento dado del proceso dinámico (incorporación política) mediante el cual los inmigrantes convergen, en términos políticos, con la población de la sociedad de acogida. Idealmente, este proceso acaba cuando el factor de la nacionalidad (vernácula o extranjera) no es el que explica la existencia de las diferencias entre los individuos en materia de actitudes y comportamientos políticos. En este último escenario, la marginación política no se encuentra asociada a la posesión de un valor en particular de esta variable.

En tanto, la definición operativa de la integración política ha asumido diferentes manifestaciones. Generalmente, los indicadores elegidos para su medición han intentado cubrir tanto información sobre las actitudes políticas de los inmigrantes como datos sobre el comportamiento político de los mismos. Para el caso de los adolescentes, la elección de las competencias cívicas como indicadores de la integración política respeta esta tradición. En el caso concreto de las competencias cívicas incluidas en este estudio, tres de ellas remiten a actitudes (conocimiento político, atención política y eficacia política) y otras dos proporcionan información sobre potenciales comportamientos (participación política y tolerancia política) ${ }^{8}$.

La elección de las competencias cívicas como indicador de la integración política resulta también adecuada porque, en el caso de muestras conformadas por población no adulta (aún no activas cívicamente por impedimento legal), las mismas fungen como el instrumento más adecuado para anticipar actitudes y comportamientos políticos futuros de los encuestados. El objeto de estudio de la investigación descrita en estas líneas (adolescentes inmigrantes y nativos en

8 La aplicación de las competencias cívicas también favorece la posesión de indicadores de integración política que pueden llegar a reflejar distintos niveles de esfuerzo o implicación por parte de los sujetos y distintos grados de desafío a sus patrones socio-culturales. 
la escuela secundaria española) otorga carta de naturaleza para proceder de esta forma.

Los indicadores elegidos en esta investigación para la medición de las diferentes competencias cívicas respetan lo utilizado generalmente en la literatura sobre la cuestión. Para cada una de las competencias sobre las que se recogió información mediante la aplicación de cuestionarios entre adolescentes y sus padres y/o tutores ${ }^{9}$, la estrategia utilizada ha sido la siguiente:

- Conocimiento político: se procedió a preguntar sobre información no sofisticada acerca del sistema político de la sociedad de acogida. Las preguntas para adolescentes y para padres y/o tutores diferían para evitar el trasvase de información que pudiese afectar la medición de la competencia. Las preguntas para uno y otro colectivo eran un total de 5 (cinco). Se creó una escala que otorgaba mayores valores en esta competencia a quienes respondieran correctamente a mayor cantidad de preguntas.

- Atención política: se procedió a preguntar sobre la frecuencia con la que se realizan actividades que tienen por objeto la obtención de información y la discusión sobre la realidad política. El total de preguntas, en este caso, fue de 4 (cuatro): dos de ellas referidas a actividades desarrolladas de manera solitaria y dos de ellas referidas a actividades desarrolladas en el marco familiar. La misma lógica para la redacción de preguntas fue usada en ambos tipos de cuestionarios (adolescentes y padres y/o tutores). Se creó una escala que otorgaba mayores valores en esta competencia a quienes realizarán con mayor frecuencia las actividades sobre las que se preguntaba.

- Participación política: se procedió a preguntar, en relación con situaciones concretas (una claramente vinculada al mundo de la política y otra relacionada con problemáticas socio-comunitarias), si la persona encuestada asumiría determinados comportamientos. El total de preguntas, en este caso, fue de 2 (dos). La misma lógica para la redacción de preguntas fue usada en ambos tipos de cuestionarios (adolescentes y padres y/o tutores). Se creó una escala que otorgaba mayores valores en esta competencia a quienes realizarán las dos actividades que se proponían.

9 La información sobre las competencias cívicas de padres y/o tutores es tratada en la presente investigación como variable independiente de las mismas competencias entre adolescentes. En este caso, lo que se observa es la influencia de la familia como agente de socialización política. 
- Eficacia política: se procedió a preguntar sobre ambas dimensiones de esta competencia. En relación con la faz interna, se indagó sobre si el sujeto encuestado comprendía el mundo de la política. En relación con la faz externa, se interrogó sobre la capacidad de influencia que la familia del encuestado tendría en las decisiones que emanan del gobierno. El total de preguntas, en este caso, fue de 2 (dos), una por dimensión. La misma lógica para la redacción de preguntas fue usada en ambos tipos de cuestionarios (adolescentes y padres y/o tutores). Se creó una escala que otorgaba mayores valores en esta competencia a quienes respondían positivamente a ambas preguntas.

- Tolerancia política: se procedió a preguntar sobre la aceptación de diferentes situaciones, algunas referidas a avances legales que han registrado los países occidentales en los últimos años (tolerancia política lato sensu) y otras referidas a la respuesta que se daría en contextos en los que las ideas propias podrían ser confrontadas con otras de signo opuesto (tolerancia política stricto sensu). El total de preguntas, en este caso, fue de 4 (cuatro), dos por cada tipo de tolerancia. La misma lógica para la redacción de preguntas fue usada en ambos tipos de cuestionarios (adolescentes y padres y/o tutores). Se creó una escala que otorgaba mayores valores en esta competencia a quienes respondían positivamente a todas las preguntas.

La próxima tabla resume las estrategias que se utilizaron para proceder a la operacionalización de estas competencias cívicas como indicadores de la integración política. 


\section{Tabla I}

Operacionalización de las competencias civicas como indicadores de la integración política

\begin{tabular}{|c|c|c|c|c|}
\hline $\begin{array}{c}\text { Competencia } \\
\text { cívica }\end{array}$ & $\begin{array}{l}\text { Tipo de pre- } \\
\text { guntas }\end{array}$ & $\begin{array}{c}\text { Número de } \\
\text { preguntas }\end{array}$ & $\begin{array}{c}\text { Valor } \\
\text { Mínimo }\end{array}$ & $\begin{array}{c}\text { Valor } \\
\text { Máximo }\end{array}$ \\
\hline $\begin{array}{l}\text { Conocimiento } \\
\text { político }\end{array}$ & $\begin{array}{l}\text { Información } \\
\text { acerca del sis- } \\
\text { tema político de } \\
\text { la sociedad de } \\
\text { acogida }\end{array}$ & 5 & 0 & 3 \\
\hline $\begin{array}{l}\text { Atención polí- } \\
\text { tica }\end{array}$ & $\begin{array}{l}\text { Frecuencia con } \\
\text { la que se reali- } \\
\text { zan actividades } \\
\text { para la obten- } \\
\text { ción de informa- } \\
\text { ción y la discu- } \\
\text { sión sobre la } \\
\text { realidad politica }\end{array}$ & $4(2$ y 2$)$ & 0 & 3 \\
\hline $\begin{array}{l}\text { Participación } \\
\text { politica }\end{array}$ & $\begin{array}{l}\text { Decisión afirma- } \\
\text { tiva/negativa de } \\
\text { participación en } \\
\text { determinados } \\
\text { contextos }\end{array}$ & 2 & 0 & 3 \\
\hline $\begin{array}{l}\text { Eficacia poli- } \\
\text { tica }\end{array}$ & $\begin{array}{l}\text { Dimensión in- } \\
\text { terna: Compren- } \\
\text { sión del mundo } \\
\text { político } \\
\text { Dimensión ex- } \\
\text { terna: Capaci- } \\
\text { dad de influen- } \\
\text { cia en el mundo } \\
\text { político }\end{array}$ & $2(1 \mathrm{y} 1)$ & 0 & 3 \\
\hline $\begin{array}{l}\text { Tolerancia po- } \\
\text { lítica }\end{array}$ & $\begin{array}{l}\text { Lato sensu: } \\
\text { Aceptación de } \\
\text { avances legisla- } \\
\text { tivos } \\
\text { Stricto sensu: } \\
\text { Aceptación de } \\
\text { exposición a po- } \\
\text { siciones opues- } \\
\text { tas a las propias }\end{array}$ & $4(2$ y 2$)$ & 0 & 3 \\
\hline
\end{tabular}

Fuente: Elaboración propia. 
Diferentes factores y agentes han sido explorado como eventuales causantes de los niveles de competencias cívicas entre los adolescentes autóctonos e inmigrantes. La religiosidad se encuentra entre las mismas. La siguiente tabla resume las estrategias que se utilizaron para proceder a la selección y operacionalización de estas variables independientes.

\section{Tabla II}

Variables independientes exploradas

\begin{tabular}{|c|c|c|c|}
\hline $\begin{array}{c}\text { Variables } \\
\text { indepen- } \\
\text { dientes ex- } \\
\text { ploradas } \\
\end{array}$ & Background teórico & $\begin{array}{l}\text { Tipo de } \\
\text { Preguntas }\end{array}$ & $\begin{array}{l}\text { Unidad de } \\
\text { observación }\end{array}$ \\
\hline \multicolumn{4}{|c|}{ Factores sociodemográficos } \\
\hline $\begin{array}{l}\text { Condición } \\
\text { migratoria }\end{array}$ & $\begin{array}{l}\text { Estudios sobre actitudes y } \\
\text { comportamientos políticos } \\
\text { de los inmigrantes en dis- } \\
\text { ciplinas diversas (Ciencia } \\
\text { Política, Psicología Polí- } \\
\text { tica, etc.) (Torney-Purta et } \\
\text { al. 2007; Morales y } \\
\text { Giugni, 2011) }\end{array}$ & $\begin{array}{l}\text { Pregunta abierta so- } \\
\text { bre } \\
\text { país de nacimiento } \\
\text { (adolescentes) y } \\
\text { nacionalidad de ori- } \\
\text { gen (tutores) }\end{array}$ & $\begin{array}{l}\text { Adolescentes } \\
\text { Padres y/o } \\
\text { tutores }\end{array}$ \\
\hline $\begin{array}{l}\text { Tiempo de } \\
\text { residencia } \\
\text { en sociedad } \\
\text { de acogida } \\
\end{array}$ & $\begin{array}{l}\text { Teoría de la exposición de } \\
\text { la resocialización política } \\
\text { (White et al., 2008) }\end{array}$ & $\begin{array}{l}\text { Pregunta abierta so- } \\
\text { bre cantidad de años } \\
\text { que se ha residido en } \\
\text { sociedad de acogida }\end{array}$ & $\begin{array}{l}\text { Adolescentes } \\
\text { Padres y/o } \\
\text { tutores }\end{array}$ \\
\hline $\begin{array}{l}\text { Status socio- } \\
\text { económico }\end{array}$ & $\begin{array}{l}\text { Teoría de la transferencia } \\
\text { de la resocialización polí- } \\
\text { tica (White } \text { et al., 2008) }\end{array}$ & $\begin{array}{l}\text { Preguntas sobre sta- } \\
\text { tus socio-económico } \\
\text { de padres y/o tutores: } \\
\text { Nivel educativo (ce- } \\
\text { rrada) } \\
\text { Nivel de Ingreso (ce- } \\
\text { rrada) } \\
\text { Ocupación (abierta) }\end{array}$ & $\begin{array}{l}\text { Adolescentes } \\
\text { Padres y/o } \\
\text { tutores }\end{array}$ \\
\hline $\begin{array}{l}\text { Lengua ha- } \\
\text { blada en el } \\
\text { hogar }\end{array}$ & $\begin{array}{l}\text { Brady et al., } 1995 \\
\text { Leighley y Vedlitz, } 1999\end{array}$ & $\begin{array}{l}\text { Pregunta abierta so- } \\
\text { bre lengua hablada en } \\
\text { el hogar }\end{array}$ & Adolescentes \\
\hline $\begin{array}{l}\text { Nivel de Re- } \\
\text { ligiosidad }\end{array}$ & $\begin{array}{l}\text { Djupe y Tobin, } 2001 \\
\text { Jones-Correa y Leal, } 2001\end{array}$ & $\begin{array}{l}\text { Pregunta cerrada so- } \\
\text { bre frecuencia en la } \\
\text { participación en acti- } \\
\text { vidades vinculadas al } \\
\text { culto }\end{array}$ & $\begin{array}{l}\text { Adolescentes } \\
\text { Padres y/o } \\
\text { tutores }\end{array}$ \\
\hline
\end{tabular}




\begin{tabular}{|c|c|c|c|}
\hline \multicolumn{4}{|c|}{ Factores psicológicos } \\
\hline $\begin{array}{l}\text { Actitudes } \\
\text { pro-sociales }\end{array}$ & Metz y Youniss, 2005 & $\begin{array}{l}\text { Pregunta cerrada so- } \\
\text { bre frecuencia en la } \\
\text { que se incurre en ac- } \\
\text { ciones vinculadas a } \\
\text { estas actitudes (empa- } \\
\text { tía y disposición a la } \\
\text { ayuda). }\end{array}$ & $\begin{array}{l}\text { Adolescentes } \\
\text { Padres y/o } \\
\text { tutores }\end{array}$ \\
\hline \multicolumn{4}{|c|}{ Agentes de socialización } \\
\hline Familia & $\begin{array}{l}\text { Estudios clásicos y con- } \\
\text { temporáneos de socializa- } \\
\text { ción política en Ciencia } \\
\text { Política y Psicología } \\
\text { (Easton y Dennis, 1967; } \\
\text { Torney-Purta et al. 2007) }\end{array}$ & $\begin{array}{l}\text { Preguntas cerradas } \\
\text { sobre competencias } \\
\text { cívicas (ver cuadro } \\
2.1 \text { ) }\end{array}$ & $\begin{array}{l}\text { Adolescentes } \\
\text { Padres y/o } \\
\text { tutores }\end{array}$ \\
\hline Escuela & $\begin{array}{l}\text { Estudios clásicos y con- } \\
\text { temporáneos de socializa- } \\
\text { ción política en Ciencia } \\
\text { Política y Psicología } \\
\text { (Langton y Jennings, 1968; } \\
\text { Dudley y Gitelson, 2002) }\end{array}$ & $\begin{array}{l}\text { Preguntas sobre: Ra- } \\
\text { tio de inmigran- } \\
\text { tes/nativos por centro } \\
\text { educativo (pregunta } \\
\text { abierta) } \\
\text { Itinerario formativo } \\
\text { de la institución (pre- } \\
\text { gunta cerrada) Fre- } \\
\text { cuencia de uso de in- } \\
\text { novaciones pedagógi- } \\
\text { cas en la enseñanza } \\
\text { de asignaturas vincu- } \\
\text { ladas a la formación } \\
\text { cívica (pregunta ce- } \\
\text { rrada) } \\
\text { Frecuencia de discu- } \\
\text { sión sobre política en } \\
\text { los salones de clase } \\
\text { (pregunta cerrada) }\end{array}$ & $\begin{array}{l}\text { Adolescentes } \\
\text { Directivos de } \\
\text { centro educa- } \\
\text { tivo }\end{array}$ \\
\hline $\begin{array}{l}\text { Grupo de } \\
\text { Pares }\end{array}$ & $\begin{array}{l}\text { Estudios clásicos y con- } \\
\text { temporáneos de socializa- } \\
\text { ción política en Ciencia } \\
\text { Política y Psicología } \\
\text { (Niemi y Sobieszek, 1977; } \\
\text { Ryan, 2001) }\end{array}$ & $\begin{array}{l}\text { Preguntas cerradas } \\
\text { sobre competencias } \\
\text { cívicas (ver cuadro } \\
2.1 \text { ) }\end{array}$ & Adolescentes \\
\hline
\end{tabular}

Fuente: Elaboración propia 


\section{DATOS, MÉTODOS E HIPÓTESIS}

En el marco de esta investigación, se visitaron 11 ciudades españolas ${ }^{10}$. En la muestra de centros, sólo se incluyó a institutos públicos de educación secundaria. Esto es producto de que, según reporta el Instituto Nacional de Estadística (INE), es la escuela pública la que históricamente ha recibido en mayor medida al alumnado de origen inmigrante. Según Alegre y Subirats, para el año 2007 (un año antes de iniciada la recolección de datos), el 81,4\% de los alumnos inmigrantes concurrían a estos centros y sólo el 18,6\% lo hacía a centros privados y concertados.

La selección de los centros educativos fue llevada a cabo en función de información provista por los Departamentos de Estadística de las Consejerías de Educación de las Comunidades Autónomas. Inicialmente, por cada ciudad visitada, se incluía en la muestra a tres centros educativos (aquellos tres en los que hubiese mayor porcentaje de alumnado inmigrante sobre el total de alumnos por urbe $)^{11}$. El proceder de esa manera garantizaba que se tuviera suficiente variabilidad de orígenes nacionales. La mayoría de los centros educativos en los que se procedió a encuestar se ubicaba en distritos urbanos en los que habitan familias pertenecientes a los estratos medio-bajos de la sociedad ${ }^{12}$.

Lo descrito permite percibir que la muestra creada no ha tenido intención de generalización de los resultados de la investigación sino, por ser un estudio de tipo pionero, sólo pretende la comprobación de hipótesis sustantivas. Para la preparación de los cuestionarios para la recolección de los datos, se tuvo en cuenta lo que se ha utilizado hasta el momento en investigaciones semejantes. A tales efectos, ha sido especialmente relevante la revisión de la experiencia anglosajona en la materia. Una vez preparados los cuestionarios, fueron probados en una escuela secundaria de la ciudad de Salamanca ${ }^{13}$. Esta prueba permitió

10 Las ciudades que fueron visitadas durante la recogida de datos son Ávila, Barcelona, Burgos, Madrid, Málaga, Salamanca, Segovia, Sevilla, Valencia, Valladolid y Zamora. Las grandes ciudades que conforman la muestra (Madrid, Barcelona, Valencia, Sevilla y Málaga) fueron escogidas por dos motivos: son las urbes más pobladas de España según el INE y las que mayor diversidad de población inmigrante presentan según también la fuente referida. El resto de las ciudades (capitales de diferentes provincias castellanas) fue incluido en la muestra por pertenecer a un distrito político con exigua población inmigrante.

11 La cuantía de 3 centros por ciudad obedece básicamente a motivos logísticos, es decir, a las "posibilidades reales" de cobertura de institutos por parte del equipo de investigación.

12 A pesar de cierta semejanza en el perfil socioeconómico de los distritos en los que se asientan las escuelas, ello no implica teóricamente que los adolescentes y padres (o tutores) encuestados presenten un status socioeconómico perfectamente coincidente. Por tal motivo, el status socioeconómico ha sido incluido como variable cuya influencia sobre la integración política es evaluada empíricamente.

13 La prueba del cuestionario fue realizada en el Instituto de Educación Secundaria Vaguada de la Palma (Plaza de la Palma, s/n) en marzo de 2008. 
asegurar que el lenguaje utilizado en su redacción resultaba asequible para los grupos objeto de estudio. Al mismo tiempo, se pudo comprobar la extensión máxima requerida para su aplicación.

Los datos fueron recogidos durante el bienio 2008-2009 ${ }^{14}$. En cada centro educativo, se aplicaron cuestionarios a tres grupos de personas: adolescentes (nativos e inmigrantes), padres y/o tutores (nativos e inmigrantes) y directivos. Los cuestionarios eran autoadministrados y podían ser respondidos en un tiempo máximo de diez minutos. Los alumnos los respondían en presencia de los investigadores o de los docentes/directivos del centro que colaboraban con los investigadores. Los estudiantes a los que se pasaba la encuesta se encontraban en el último año del bachillerato o, en su defecto, en el último año de la Educación Secundaria Obligatoria (ESO).

Los cuestionarios de padres y/o tutores eran entregados a los colaboradores por centro. Los últimos se encargaban de hacerlo llegar a los destinarios. Estos cuestionarios eran respondidos en los respectivos hogares y devueltos a los colaboradores. A posteriori, éstos remitían la documentación pre-franqueada vía correo postal al equipo de investigación. Los siguientes datos globales resumen la información sobre la muestra finalmente obtenida:

- 516 adolescentes entre nativos (362) e inmigrantes $(154)^{15}$

- 32 nacionalidades diferentes ${ }^{16}$

- 6 regiones diferentes de background/procedencia socio-cultural ${ }^{17}$

- 211 padres y/o tutores

- 18 escuelas secundarias

Para analizar cómo la religiosidad y el resto de las variables independientes podrían estar causando diferencias en materia de competencias cívicas e integración política entre los colectivos vernáculo y extranjero, se hizo uso de una técnica de estadística multivariante: el Análisis de Correlación Canónica (ACC). El mismo fue utilizado para ver, concretamente, cómo se vinculan los factores explorados con cada una de las competencias cívicas.

El uso del análisis de correlación canónica resultó apropiado a los fines de esta investigación porque permite detectar cuál es el tipo de relación existente

14 Concretamente, los datos fueron recogidos entre abril de 2008 y abril de 2009.

15 En esta muestra, se ha considerado inmigrantes a quienes han nacido fuera de España.

16 Los países de origen de los individuos incluidos en la muestra son España, Marruecos, Francia, Colombia, Uruguay, Bolivia, Ecuador, Argentina, Brasil, Cuba, Grecia, Venezuela, Filipinas, Alemania, Ucrania, Rusia, Perú, Bélgica, Portugal, Libia, Pakistán, República Dominicana, China, Italia, Rumania, Gran Bretaña, México, Moldavia, Suiza, Costa Rica, Bulgaria y Argelia.

17 Siguiendo la usanza en la materia, se han considerado regiones diferentes a las siguientes: España, América Latina, UE-15 más Suiza, Europa del Este, Mundo Árabe/Islámico y Extremo Oriente. 
entre dos grupos diferentes de variables desde el punto de vista teórico (uno de ellos independiente y otro de ellos dependiente). Como técnica de dependencia, ayuda a maximizar las correlaciones entre combinaciones lineares de variables. Aunque relativamente desconocida hasta hace un par de años, se afirma que, para estos casos, es el instrumento más potente (Hair, Anderson, Tatham y Black, 2007). La forma general de la correlación canónica se expresa de la siguiente manera:

$$
\mathrm{Y}_{1}+\mathrm{Y}_{2}+\mathrm{Y}_{3}+\cdots+\mathrm{Y}_{n}=\mathrm{X}_{1}+\mathrm{X}_{2}+\mathrm{X}_{3}+\cdots+\mathrm{X}_{\mathrm{n}}
$$

Esta técnica cuenta con numerosas ventajas (Hair et al., 2007). En primer lugar, permite predecir, de manera simultánea, el comportamiento de múltiples variables dependientes a partir de la existencia de múltiples variables independientes. Ello ayuda a responder de mejor manera a la complejidad de la realidad social que se refleja metodológicamente en la multidimensionalidad de los conceptos con los que se trabaja. En segundo lugar, impone un menor número de restricciones sobre los tipos de datos con los cuales es posible trabajar. En tal sentido, permite la inclusión, dentro de los grupos de variables independientes y dependientes, tanto de factores métricos como no métricos.

En tercer lugar, el uso de correlación canónica disminuye la probabilidad de cometer errores de Tipo I, es decir, aquél vinculado al hallazgo de relaciones significativas cuando éstas no existen. En cuarto lugar, permiten detectar, al interior de cada grupo o set de variables, cuál es (son) el (los) factor(es) que más contribuye(n) a las relaciones que son halladas. De esa manera, a posteriori, pueden construirse otros modelos (como la regresión múltiple) que incluyan sólo a aquellas variables dotadas de significación estadística.

En el caso concreto de esta investigación, el análisis de correlación canónica pudo ser utilizado porque se cumplen los requisitos exigidos para su implementación (Hair et al., 2007). Por un lado, se tienen, al menos, diez observaciones por variable. De esa manera, se evita lo que se llama "sobreajuste" de los datos. Por otro lado, se respetaban los supuestos que se demandan a los datos para proceder a su aplicación ${ }^{18}$ : linealidad, homocedasticidad y multicolinealidad.

La hipótesis de partida en relación con el tipo de vínculo previsto entre religiosidad y competencias cívicas preveía que, a mayores niveles de práctica religiosa de los adolescentes, se encontrarían mayores registros en competencias

18 El supuesto de normalidad no es tan exigente como los otros aquí mencionados. Sin embargo, se recomienda que, en el caso de hallarse variables no normales, las mismas procedan a ser normalizadas (Hair et al., 2007). 
cívicas (integración política) tanto entre nativos como entre inmigrantes. La única excepción a este supuesto, en base a la literatura previa, se esperaba para tolerancia política (Niemi y Chapman, 1998; Eisenstein, 2006).

\section{ANÁLISIS Y DISCUSIÓN}

En el análisis de la muestra global, es decir, la conformada por sujetos tanto inmigrantes como nativos, tres funciones canónicas presentaron significación estadística (p valor igual a .000) y $\mathrm{R}_{\mathrm{c}}$ por encima de $30 \%$. Sin embargo, sólo una de ellas presentó tanto un $\mathrm{R}_{\mathrm{c}}{ }^{2}$ elevado $(36,7 \%)$ como significación práctica. Esta función canónica tuvo un índice de redundancia de $11,4 \%{ }^{19}$. Este último guarismo refleja un valor más que aceptable para este tipo de técnicas (Clark, 2006; Glatfelter, 2009). La tabla III resume los resultados de este test multivariante sobre este conjunto muestral.

Para la selección de las variables que, dentro de cada set, poseían significación estadística, se utilizó la guía proporcionada por Hair et al. 2007. En concreto, para un tamaño muestral mayor a 350 individuos (516 en el caso de la muestra global), las cargas superiores a 0.30 son consideradas relevantes para un nivel de significación de .05. Usando este criterio, 7 variables independientes ( $70 \%$ del total) y 4 competencias cívicas $(80 \%$ del total) tuvieron significación estadística. Ambos resultados confirman lo apropiado de haber integrado los sets de variables del modo en el que fueron constituidos.

En relación con las variables independientes significativas, todas, con excepción de "Nivel de Religiosidad", presentaron un comportamiento en relación con las competencias cívicas acorde a lo descrito por la literatura. En tanto, todas las competencias cívicas se mueven en un idéntico sentido. Su coeficiente de adecuación es de $30.9 \%$. Estos resultados avalan la creación de un índice que, como en el caso de la Integración Política, se encuentra conformado por cada una de ellas.

¿Qué delata la aplicación del Análisis de Correlación Canónica sobre las variables implicadas en la función canónica que reúne las condiciones de significación estadística y práctica? En primer lugar, en el caso de la "Condición Migratoria", la carga canónica (-.556) refleja que el ser nativo (categoría de referencia) es un predictor de la posesión de las competencias cívicas. Esta pauta

19 Este índice de redundancia sólo refleja la relación relevante desde el punto de vista teórico, es decir, aquélla que hace depender a las competencias cívicas de los factores y agentes de socialización sometidos a estudio. 
podría anticipar la distribución, durante la adultez, de estos atributos cívicos (Verba et al. 1995). Al mismo tiempo, la "Cantidad de Años de Residencia en la Sociedad de Acogida" se encuentra asociada positivamente (.687) con las competencias cívicas (es decir, a más años de residencia, mayores niveles en la posesión de las mismas).

En tanto, el "Nivel de Religiosidad" se encuentra negativamente asociado (-.469) a la posesión de competencias cívicas. En otras palabras, los sujetos más religiosos son los que menos atributos cívicos presentan. Política y religión parecen encontrarse en terrenos opuestos. Las experiencias comunitarias, bajo el marco cultual, no parecen estimular un interés por la realidad política ${ }^{20}$. Ello se encuentra en las antípodas de lo sugerido por la literatura sobre la cuestión (Djupe y Grant, 2001).

En esta muestra global, el "Género" (.052) es la variable que menos se encuentra vinculada a la posesión de competencias cívicas. Patrón semejante asumen el "Status Socioeconómico" (.176) y "Lengua Hablada en el Hogar" (.232). Estos son los tres factores socio-demográficos que no alcanzan significación estadística.

En relación con el único factor psico-social incluido en el set de variables independientes ("Actitudes Pro-Sociales"), se halla que los individuos más empáticos y más dispuestos a ayudar son los que presentan mayor bagaje de competencias cívicas. Su carga canónica es de .399. De esta manera, se confirma, como sugiere la literatura, que lo político se haya antecedido por la posesión de predisposiciones que vinculan a los individuos con su entorno social más próximo (Metz y Youniss, 2005).

El Análisis de Correlación Canónica arroja entre sus resultados que los tres agentes de socialización política incluidos son relevantes a la hora de producir competencias cívicas. El más importante es "Grupo de Pares" con una carga canónica de .672. Luego, se ubica "Padres" con .380. A mayores niveles de "Integración Política" de compañeros de escuela y de padres y/o tutores, mayores niveles de competencias cívicas registrarán los adolescentes. En tanto, la asistencia a "Escuelas" más abiertas tiende a propiciar adolescentes más competentes cívicamente. Con estos hallazgos, la evidencia empírica de los estudios norteamericanos clásicos en socialización política es reconfirmada en esta muestra de adolescentes nativos e inmigrantes recogida en España (Easton y Dennis, 1967).

20 De hecho, aplicando "Correlaciones de Pearson" a la vinculación de esta variable con todas las competencias cívicas, la relación es siempre de signo negativo. 
Según los resultados de haber aplicado este test estadístico, el perfil de la persona poseedora de las competencias cívicas en esta muestra global es el de nativo, más asentado en la sociedad de acogida ${ }^{21}$, menos religioso, con marcadas actitudes pro-sociales e influido positivamente por los tres agentes de socialización política estudiados (padres, grupo de pares y escuela). Si bien este resultado es poco alentador en relación con los niveles de atributos cívicos poseídos por los adolescentes extranjeros, se percibe que existen dos resortes/instancias sobre los que eventualmente puede incidirse para la propiciación de mejores registros sobre el particular: actitudes pro-sociales y agentes de socialización política. El diseño y ejecución consciente de políticas ad hoc tanto educativas como de gestión de la migración es un mecanismo que debe ser considerado estratégicamente a tales efectos ${ }^{22}$.

\section{Tabla III}

Medidas de ajuste global del modelo para el Análisis de Correlación Canónica (Muestra Global)

\begin{tabular}{|c|c|c|}
\hline $\begin{array}{c}\text { Factores, Agentes y } \\
\text { Competencias }\end{array}$ & Variables & Cargas Canónicas \\
\hline \multirow[t]{6}{*}{$\begin{array}{c}\text { Factores Socio- } \\
\text { Demográficos } \\
(S E T \text { 1) }\end{array}$} & $\begin{array}{l}\text { Género } \\
(0=\text { Varón } \\
1=\text { Mujer })\end{array}$ &, 052 \\
\hline & $\begin{array}{c}\text { Condición Migratoria } \\
(0=\text { Nativo } \\
1=\text { Inmigrante })\end{array}$ &,- 556 \\
\hline & $\begin{array}{l}\text { Cantidad de años de residen- } \\
\text { cia en sociedad de acogida }\end{array}$ & ,687 \\
\hline & Status socioeconómico & , 176 \\
\hline & $\begin{array}{c}\text { Lengua Hablada en el Hogar } \\
(0=\text { No Nativa } \\
1=\text { Nativa })\end{array}$ & 232 \\
\hline & Nivel de Religiosidad &,- 469 \\
\hline $\begin{array}{c}\text { Factores Psico-Sociales } \\
\text { (SET 1) }\end{array}$ & Actitudes Pro-Sociales & ,399 \\
\hline \multirow{2}{*}{$\begin{array}{c}\text { Agentes de Socializa- } \\
\text { ción }\end{array}$} & Padres &, 380 \\
\hline & Grupo de Pares &, 672 \\
\hline
\end{tabular}

21 En el caso de los nativos, este más prolongado asentamiento en la sociedad de acogida puede ser entendido como más edad cronológica.

22 La creación de atmósferas escolares más abiertas e inclusivas es un ejemplo en el terreno de las políticas educativas. La estimulación de las actitudes pro-sociales, mediante la formación en valores, es otro. El fomento de la participación de los inmigrantes (padres e hijos) en cursos de inmersión en la vida política de la sociedad de acogida es un ejemplo de políticas en el plano de la gestión de la inmigración. 


\begin{tabular}{|c|c|c|c|}
\hline (SET 1) & Escuela & \multicolumn{2}{|c|}{331} \\
\hline \multicolumn{2}{|c|}{$\mathbf{R}_{\mathbf{c}}$} & \multicolumn{2}{|c|}{$60.6 \%$} \\
\hline \multicolumn{2}{|c|}{$\mathbf{R}^{2}{ }^{2}$} & \multicolumn{2}{|c|}{$36,7 \%$} \\
\hline \multicolumn{2}{|c|}{ Nivel de significación } & \multicolumn{2}{|c|}{0.000} \\
\hline \multicolumn{2}{|c|}{ Wilk's Lambda } & \multicolumn{2}{|c|}{.469} \\
\hline \multicolumn{2}{|c|}{$\mathrm{Chi}^{2}$} & \multicolumn{2}{|c|}{328.169} \\
\hline \multicolumn{2}{|c|}{ Df } & \multicolumn{2}{|c|}{50} \\
\hline \multicolumn{2}{|c|}{ Índices de redundancia } & $7,2 \%$ & $11,4 \%$ \\
\hline \multicolumn{2}{|c|}{ Coeficientes de adecuación } & $19.5 \%$ & $30,9 \%$ \\
\hline \multirow{5}{*}{$\begin{array}{c}\text { Competencias cívicas } \\
\text { (SET 2) }\end{array}$} & Conocimiento Político & \multicolumn{2}{|c|}{, 733} \\
\hline & Atención Política & \multicolumn{2}{|c|}{, 330} \\
\hline & Participación Política & \multicolumn{2}{|c|}{.554} \\
\hline & Eficacia Política & \multicolumn{2}{|c|}{,196 } \\
\hline & Tolerancia Política & \multicolumn{2}{|c|}{, 743} \\
\hline
\end{tabular}

Nota I: en algunos casos, los signos fueron revertidos para favorecer la comprensión de los datos.

Nota II: los signos señalan el carácter directo o inverso de la relación entre las diferentes variables independientes y dependientes.

Nota III: las variables señaladas en rojo son aquéllas estadísticamente significativas (con una carga factorial por encima de 0.30 ).

Fuente: Elaboración propia.

Una vez analizada la muestra global, se procedió a la realización de este test multivariante sobre la muestra de nativos. Para este caso, como en el anterior, tres funciones canónicas presentaron significación estadística ( $\mathrm{p}$ valor igual a .000) y $\mathrm{R}_{\mathrm{c}}$ por encima de $30 \%$. Otro rasgo semejante es que sólo una de ellas presentó un $\mathrm{R}_{\mathrm{c}}{ }^{2}$ elevado $(31,36 \%)$ y significación práctica. Esta función canónica tuvo un índice de redundancia de $9,8 \%{ }^{23}$ (1.6 puntos porcentuales por debajo de la muestra global). Este guarismo refleja también aquí un valor más que aceptable para este tipo de técnicas (Clark, 2006; Glatfelter, 2009). La Tabla IV resume los resultados de este test multivariante sobre este conjunto muestral.

Según la guía proporcionada por Hair et al. 2007, para un tamaño muestral mayor a 350 individuos (362 en el caso de la muestra de nativos), las cargas superiores a 0.30 son consideradas relevantes para un nivel de significación de .05 . Usando este criterio, 6 variables independientes $(66,6 \%$ del total) y 5 competencias cívicas (100\% del total) tuvieron significación estadística. Ambos resultados reconfirman, para este subconjunto muestral, lo correcto de haber integrado los sets de variables del modo en el que fueron compuestos.

23 Este índice de redundancia sólo refleja la relación relevante desde el punto de vista teórico, es decir, aquélla que hace depender a las competencias cívicas de los factores y agentes de socialización sometidos a estudio. 
Las competencias cívicas se mueven, todas ellas, en un idéntico sentido. Su coeficiente de adecuación es de $31.3 \%$. Estos últimos hallazgos contribuyen a avalar la creación de un índice que, como en el caso de la Integración Política, se encuentra conformado por los mencionados atributos cívicos.

¿Cuáles son los hallazgos del Análisis de Correlación Canónica sobre las variables incorporadas en la función canónica que combina tanto significación estadística como práctica? En primer lugar, "Cantidad de Años de Residencia en la Sociedad de Acogida" se encuentra asociada positivamente con las competencias cívicas. Para el caso de los nativos, esta variable puede ser considerada una especie de proxy de "Edad". Por tanto, a mayor edad de los adolescentes nativos, mayor nivel de competencias cívicas.

Siguiendo con las variables independientes significativas, nuevamente "Nivel de Religiosidad" es la única que presenta un comportamiento en relación con las competencias cívicas distinto a lo descrito por la literatura. Esta variable se encuentra negativamente vinculada (-.431) a la posesión de competencias cívicas. En otras palabras, los sujetos más religiosos son los que menos desarrollan competencias cívicas. En tanto, la diferencia entre la muestra global y la conformada sólo por autóctonos es ínfima para esta variable (3.8\%). Uno y otro conjunto coinciden, entonces, en la tendencia asumida por este factor de tipo socio-demográfico. Contrariamente a lo sugerido por la evidencia empírica previa, la práctica religiosa aleja a los nativos del mundo de lo político. Se descarta entonces la hipótesis de trabajo que relacionaba de manera directa a ambas variables.

En esta muestra nativa, el "Género" (.086) es otra vez la variable que menos se encuentra vinculada a la posesión de competencias cívicas. Como aconteció con la muestra global, tampoco presenta significación estadística el "Status Socioeconómico" (.216).

En relación con el único factor psico-social incluido en el set de variables independientes ("Actitudes Pro-Sociales"), se encuentra nuevamente que los individuos más empáticos y más dispuestos a ayudar son los que presentan mayores niveles de competencias cívicas. La carga canónica es, para esta variable, de .517. La muestra nativa supera, en $11.8 \%$, a la muestra global para esta variable. Con este hallazgo, es posible afirmar que la dimensión política se haya antecedida por la posesión de tendencias o actitudes que hacen de los individuos sujetos más interesados por su entorno más próximo.

Así mismo, el Análisis de Correlación Canónica concluye una vez más que los tres agentes de socialización política incluidos son importantes en tanto generadores de competencias cívicas. El más importante es "Grupo de Pares" con 
una carga canónica de .578. Luego, se ubica "Padres" con .464. Igual que en el caso de la muestra global, estos registros deben ser comprendidos como que a mayores niveles de "Integración Política" de compañeros de escuela y de padres y/o tutores, mayores niveles de competencias cívicas registran los adolescentes nativos ${ }^{24}$. En tanto, la pertenencia a "Escuelas" más abiertas tiende a producir adolescentes autóctonos más competentes cívicamente. Estos descubrimientos confirman la evidencia empírica aportada por los estudios norteamericanos clásicos en materia de actuación de los agentes tradicionales de socialización política.

Según los resultados de haber aplicado este test estadístico, el perfil de la persona poseedora de las competencias cívicas en esta muestra de estudiantes autóctonos es el de adolescentes, con mayor edad, menos religioso, con marcadas actitudes pro-sociales e influido positivamente por los tres agentes de socialización política estudiados (padres, grupo de pares y escuela). La pauta hallada, entre los nativos, reconfirma la importancia de actuar sobre dos resortes concretos para el logro del incremento de las competencias cívicas entre los adolescentes: actitudes pro-sociales y agentes de socialización.

Tabla IV

Medidas de ajuste global del modelo para el Análisis de Correlación Canónica (Muestra Nativos)

\begin{tabular}{|c|c|c|}
\hline $\begin{array}{c}\text { Factores, Agentes y } \\
\text { Competencias }\end{array}$ & Variables & $\begin{array}{c}\text { Cargas } \\
\text { Canónicas }\end{array}$ \\
\hline \multirow[t]{4}{*}{$\begin{array}{c}\text { Factores Socio- } \\
\text { Demográficos } \\
(S E T \text { 1) }\end{array}$} & $\begin{array}{l}\text { Género } \\
(0=\text { Varón } \\
1=\text { Mujer })\end{array}$ & .086 \\
\hline & $\begin{array}{c}\text { Cantidad de años de resi- } \\
\text { dencia en sociedad de } \\
\text { acogida }\end{array}$ & .460 \\
\hline & Status socioeconómico & .216 \\
\hline & \multicolumn{2}{|l|}{ Nivel de } \\
\hline $\begin{array}{c}\text { Factores Psico-Sociales } \\
\text { (SET 1) }\end{array}$ & Actitudes Pro-Sociales & .517 \\
\hline \multirow{3}{*}{$\begin{array}{c}\text { Agentes de Socialización } \\
\text { (SET 1) }\end{array}$} & Padres & .464 \\
\hline & Grupo de Pares & .578 \\
\hline & Escuela & .339 \\
\hline
\end{tabular}

24 La carga canónica positiva confirma las hipótesis que vinculan las competencias cívicas de los hijos con la integración política de sus padres. 


\begin{tabular}{|c|c|c|c|}
\hline \multicolumn{2}{|c|}{$\mathbf{R}_{\mathbf{c}}$} & \multicolumn{2}{|c|}{$56 \%$} \\
\hline \multicolumn{2}{|c|}{$\mathbf{R c}^{2}$} & \multicolumn{2}{|c|}{$31,3 \%$} \\
\hline \multicolumn{2}{|c|}{ Nivel de significación } & \multicolumn{2}{|c|}{0.000} \\
\hline \multicolumn{2}{|c|}{ Wilk's Lambda } & \multicolumn{2}{|c|}{.517} \\
\hline \multicolumn{2}{|c|}{$\mathrm{Chi}^{2}$} & \multicolumn{2}{|c|}{193.438} \\
\hline \multicolumn{2}{|c|}{ df } & \multicolumn{2}{|c|}{45} \\
\hline \multicolumn{2}{|c|}{ Índices de redundancia } & $5 \%$ & $9.8 \%$ \\
\hline \multicolumn{2}{|c|}{ Coeficientes de adecuación } & $15.9 \%$ & $31,3 \%$ \\
\hline \multirow{5}{*}{$\begin{array}{c}\text { Competencias cívicas } \\
\text { (SET 2) }\end{array}$} & Conocimiento Político & \multicolumn{2}{|c|}{.583} \\
\hline & Atención Política & \multicolumn{2}{|c|}{.374} \\
\hline & Participación Política & \multicolumn{2}{|c|}{.606} \\
\hline & Eficacia Política & \multicolumn{2}{|c|}{.426} \\
\hline & Tolerancia Política & \multicolumn{2}{|c|}{.732} \\
\hline
\end{tabular}

Nota I: en algunos casos, los signos fueron revertidos para favorecer la comprensión de los datos.

Nota II: los signos señalan el carácter directo o inverso de la relación entre las diferentes variables independientes y dependientes.

Nota III: las variables señaladas en rojo son aquéllas estadísticamente significativas (con una carga factorial por encima de 0.30).

Nota IV: Lengua Hablada en el Hogar fue eliminada del análisis por ser una constante.

Fuente: Elaboración propia.

Una vez analizadas la muestra global y el subconjunto nativo, se procedió a la realización de este test multivariante en tercer lugar sobre la muestra de adolescentes inmigrantes. Para este caso, como en los dos ya expuestos, tres funciones canónicas presentaron significación estadística ( $p$ valor igual a .000) y $R_{c}$ por encima de $30 \%$. Otro patrón similar es que sólo una de ellas presentó un $\mathrm{R}_{\mathrm{c}}{ }^{2}$ elevado $(36,36 \%)$ y significación práctica. Esta función canónica tuvo un índice de redundancia de $11,7 \%{ }^{25}$ (el más alto entre las tres muestras consideradas). Este guarismo refleja nuevamente aquí un valor más que aceptable al aplicar esta técnica (Clark, 2006; Glatfelter, 2009). La tabla V resume los resultados de este test multivariante sobre este grupo en particular.

Según la guía proporcionada por Hair et al. 2007, para un tamaño muestral mayor a 150 individuos (154 en el caso de la muestra de inmigrantes), las cargas superiores a 0.45 suelen ser consideradas relevantes para un nivel de significación de .05 . Usando este criterio, 2 variables independientes ( $22,2 \%$ del total) y 4 competencias cívicas ( $80 \%$ del total) tuvieron significación estadística. Si, en cambio, se usa como guía las cargas superiores a 0.30 (como ha pasado en las dos muestras previas), el número de variables independientes relevantes asciende a $5(55,5 \%$ sobre el total) y el de variables dependientes se mantiene constante. Este último criterio, menos conservador, es el que se ha utilizado para

25 Este índice de redundancia sólo refleja la relación relevante desde el punto de vista teórico, es decir, aquélla que hace depender a las competencias cívicas de los factores y agentes de socialización sometidos a estudio. 
la lectura de los resultados para proceder a la obtención de mejores condiciones de comparabilidad entre las tres muestras ${ }^{26}$.

Todas las competencias cívicas, excepto la "Eficacia Política"27 se movilizan en un idéntico sentido. Su coeficiente de adecuación es de $32.2 \%$. Estos últimos hallazgos refuerzan la necesidad de creación de un índice que, como en el caso de la Integración Política, se encuentra conformado por los mencionados atributos cívicos.

¿Cuáles son los hallazgos del Análisis de Correlación Canónica sobre las variables incorporadas en la función canónica que posee los dos tipos importantes de significación (estadística y práctica)? En primer lugar, tal como sugería la literatura, "Cantidad de Años de Residencia en la Sociedad de Acogida" (.498) se encuentra asociada positivamente con la posesión de las competencias cívicas. Ello implica que la teoría de la exposición, para explicar la socialización política de los inmigrantes adolescentes, encuentra evidencia empírica en esta muestra (White et al. 2008).

En relación con las variables independientes significativas, una vez más "Nivel de Religiosidad" es la única que presenta una tendencia en relación con las competencias cívicas distinta a la enunciada por la literatura. Se encuentra negativamente asociada (-.341) a la posesión de competencias cívicas. En otras palabras, los sujetos más religiosos son los que menos desarrollan competencias cívicas. La diferencia entre la muestra global y la conformada sólo por inmigrantes es para esta variable de 12.8 puntos porcentuales. Ambos conjuntos coinciden en el patrón asumido por este factor. La práctica religiosa aleja también a los inmigrantes del mundo político en la sociedad receptora. De esta manera, se rechaza la hipótesis de trabajo que vinculaba de manera directa al Nivel de Religiosidad con las competencias cívicas.

En la muestra de adolescentes extranjeros, el "Género" (.039) es otra vez la variable que menos se encuentra vinculada a la posesión de competencias cívicas. La utilización de lenguas vernáculas tampoco arroja significación estadística (-.011). Este último resultado desestima las hipótesis que presumen que la suficiencia en lenguas vernáculas por parte de los inmigrantes acarrea mejoras en los niveles de competencias cívicas (Brady et al., 1995).

26 Mike Clark, Consultor Estadístico del Departamento de Investigación y Apoyo Estadístico de la Universidad del Norte de Texas, recomienda siempre considerar como valores importantes desde el punto de vista estadístico aquellos que sean iguales a o superen el .30 en el Análisis de Correlación Canónica.

27 Esta competencia cívica no sólo presenta un signo distinto sino que su carga canónica (-.038) no llega a los niveles requeridos para ser considerada como dotada de significación estadística. 
No presenta ni significación estadística ni práctica el "Status Socioeconómico" (-.055). Por tanto, se descartan las hipótesis que hacen depender "positivamente" los niveles de competencias cívicas de los niveles de las dimensiones reseñadas de Status Socioeconómico (Bevelander y Pendakur, 2009). Este hallazgo también implica que la teoría de la transferibilidad para la explicación de la socialización política de los inmigrantes adolescentes no encuentra asidero empírico (White et al. 2008).

En relación con el único factor psico-social incluido en el set de variables independientes ("Actitudes Pro-Sociales"), se encuentra nuevamente que los individuos más empáticos y más dispuestos a ayudar son los que presentan mayores niveles de competencias cívicas. La carga canónica es, para esta variable, de .517. La muestra inmigrante supera, en $11.8 \%$, a la muestra global para esta variable. Con este hallazgo, es posible afirmar que la dimensión política se haya antecedida por la posesión de tendencias o actitudes que hacen de los individuos sujetos más interesados por su entorno más próximo.

Así mismo, el Análisis de Correlación Canónica halla que sólo los agentes de socialización política vinculados a la sociedad de acogida son importantes como dadores de competencias cívicas. El más relevante es "Grupo de Pares" con una carga canónica de $.661^{28}$. Luego, se ubica "Escuela" con .415. Ello implica que mayores niveles de "Integración Política" de compañeros de escuela y la asistencia a centros educativos más abiertos tienden a generar adolescentes inmigrantes más competentes cívicamente. Estos descubrimientos confirman la evidencia empírica que sostiene que la teoría de socialización política que mejor explica este proceso es la que pivotea en torno a la necesidad de que los inmigrantes se expongan a las reglas políticas de la sociedad de acogida. En el caso de los "Padres" como agentes de socialización, su escasa carga canónica (.266), aunque positiva, no alcanza significación estadística ${ }^{29}$.

El agente de socialización "Escuela" ha sido medido a través de una variable que es una especie de índice compuesto por diferentes dimensiones que, se supone, están relacionadas con la posesión de competencias cívicas entre los estudiantes. Para ver si estas dimensiones interactúan con las competencias cívicas como lo hace la variable genérica, se procedió a realizar "Comparaciones de Medias" o "Correlaciones de Pearson" según correspondiese en función de la naturaleza de los datos. Entre los hallazgos, se encontró, por un lado, que los

28 Con este hallazgo se confirma lo sugerido por literatura con relación a que el Grupo de Pares ejerce influencia como agente de socialización con independencia del origen étnico o nacional de los individuos influidos (Ryan, 2001).

29 La carga canónica positiva confirma las hipótesis que vinculan las competencias cívicas de los hijos con la integración política de sus padres. 
estudiantes de origen inmigrante que cursan itinerarios formativos de Ciencias Sociales poseen en mayor medida todas las competencias cívicas y que, en dos de ellas (Atención Política y Participación Política), las diferencias son estadísticamente significativas.

Por otro lado, se ha hallado que aquellas escuelas en las que se, según la percepción de los adolescentes, se discute más sobre política en clase son las que tienen estudiantes inmigrantes con registros más altos en Atención Política, Participación Política y Eficacia Política. Las otras dos dimensiones trabajadas al interior de la variable "Escuela" no alcanzan significación estadística. El porcentaje de alumnado inmigrante en cada centro educativo y la frecuencia en el uso de innovaciones pedagógicas en asignaturas de naturaleza "cívica" no se encuentran vinculados a ninguna competencia cívica.

Según los resultados de haber aplicado la correlación canónica, el perfil de la persona poseedora de las competencias cívicas en esta muestra de estudiantes inmigrantes es la de adolescentes que, habiendo vivido más tiempo en la sociedad de acogida, cuentan con marcadas actitudes pro-sociales, son menos religiosos y están influidos positivamente por los dos agentes de socialización política que representan o encarnan a la sociedad receptora (grupo de pares y escuela). El patrón encontrado, entre los inmigrantes, reconfirma la relevancia de una eventual actuación sobre dos resortes concretos para el logro del incremento de las competencias cívicas en este colectivo poblacional: actitudes prosociales y agentes de socialización. Ambas variables pueden ser eficazmente moldeadas mediante la puesta en marcha en el marco escolar de políticas ad hoc.

Tabla $\mathrm{V}$

Medidas de ajuste global del modelo para el Análisis de Correlación Canónica (Muestra Inmigrantes)

\begin{tabular}{|c|c|c|}
\hline $\begin{array}{c}\text { Factores, Agentes y } \\
\text { Competencias }\end{array}$ & Variables & Cargas Canónicas \\
\hline $\begin{array}{c}\text { Factores Socio- } \\
\text { Demográficos } \\
\text { (SET 1) }\end{array}$ & $\begin{array}{c}\text { Género } \\
(0=\text { Varón } \\
\text { 1=Mujer })\end{array}$ & .039 \\
\cline { 2 - 3 } & $\begin{array}{c}\text { Cantidad de años de residen- } \\
\text { cia en sociedad de acogida }\end{array}$ & .498 \\
\cline { 2 - 3 } & Status socioeconómico & -.055 \\
\cline { 2 - 3 } & $\begin{array}{c}\text { Lengua Hablada en el Hogar } \\
(0=\text { No Nativa } \\
1=\text { Nativa })\end{array}$ & -.011 \\
& Nivel de Religiosidad & -.341 \\
\cline { 2 - 3 } &
\end{tabular}




\begin{tabular}{|c|c|c|}
\hline $\begin{array}{c}\text { Factores Psico- } \\
\text { Sociales } \\
(S E T \text { 1) }\end{array}$ & Actitudes Pro-Sociales & .417 \\
\hline \multirow{3}{*}{$\begin{array}{c}\text { Agentes de Sociali- } \\
\text { zación } \\
(S E T \text { 1) } \\
\end{array}$} & Padres & .266 \\
\hline & Grupo de Pares & .661 \\
\hline & Escuela & .415 \\
\hline \multicolumn{2}{|l|}{  } & $60,3 \%$ \\
\hline \multicolumn{2}{|c|}{$\mathbf{R}_{c^{2}}$} & $36,3 \%$ \\
\hline \multicolumn{2}{|c|}{ Nivel de significación } & .000 \\
\hline \multicolumn{2}{|c|}{ Wilk's Lambda } & .385 \\
\hline \multicolumn{2}{|c|}{$\mathrm{Chi}^{2}$} & 126.462 \\
\hline \multicolumn{2}{|c|}{ df } & 45 \\
\hline \multicolumn{2}{|c|}{ Índices de redundancia } & $4,9 \%$ \\
\hline \multicolumn{2}{|c|}{ Coeficientes de adecuación } & $13,6 \%$ \\
\hline \multirow{5}{*}{$\begin{array}{l}\text { Competencias } \\
\text { cívicas } \\
(S E T 2)\end{array}$} & Conocimiento Político & .758 \\
\hline & Atención Política & .518 \\
\hline & Participación Política & .620 \\
\hline & Eficacia Política & -.038 \\
\hline & Tolerancia Política & .617 \\
\hline
\end{tabular}

Nota I: en algunos casos, los signos fueron revertidos para favorecer la comprensión de los datos.

Nota II: los signos señalan el carácter directo o inverso de la relación entre las diferentes variables independientes y dependientes.

Nota III: las variables señaladas en rojo son aquéllas estadísticamente significativas (con una carga factorial por encima de 0.30$)$.

Fuente: Elaboración propia.

Como pudo observarse, la religiosidad parece contraer el desarrollo de competencias cívicas que favorecen la integración política de los jóvenes inmigrantes en España como sociedad de acogida. El patrón es semejante también entre los adolescentes nativos. La relación negativa que la literatura preveía solamente para la tolerancia política es, según estos hallazgos, trasladable a la totalidad de las habilidades del tipo estudiado.

¿Qué puede estar causando estos resultados? En primer lugar, la referencia teórica sobre este tipo de investigaciones está siempre referida a lo que se llama "traditional settlement societies" y, dentro de ellas, a las de tipo anglosajón. En las sociedades construidas en base a dinámicas de "melting pot", las iglesias parecen haber asumido un rol de movilizadoras políticas que no tiene que darse necesariamente en sociedades que no tienen una trayectoria de larga data en materia de recepción de inmigración. Parece que esta también es la tendencia hallada en sociedades europeas que han antecedido a la península ibérica en la vivencia de fases de llegada masiva de inmigrantes. Es importante recordar que España ha tenido fundamentalmente un perfil neto de expulsora de población con un interregno en el que primó la recepción que cubre el periodo 1995-2008. 
Antes y después del mismo, su patrón más característico ha sido el de país emigrante. Estudios comparados que contrasten sociedades con distinta "antigüedad en materia de arribo de inmigrantes" (anglosajonas del Nuevo Mundo, guest workers societies, países del sur de Europa) en relación con el papel que juegan las iglesias como productoras de competencias cívicas podrían ayudar a dilucidar el por qué de estos datos anómalos. Quizás, las iglesias tienen que aprender, en contextos de venida de extranjeros, a desarrollar ese "know how" productor de habilidades políticas entre sus feligreses (proceso este que requiere, naturalmente, el paso del tiempo).

En segundo lugar, es importante recordar que los datos aquí expuestos fueron tomados justo al inicio de la fuerte crisis económica que golpeó a la Unión Europea y que actuó como catalizador de paralelas crisis en los sistemas políticos nacionales. Antes de la ocurrencia de este parón financiero, existía una marcada desafección entre los jóvenes encarnada en un progresivo alejamiento de la entendida como política tradicional. La caída en picada de la economía no vino sino a profundizar este proceso que provocó la aparición de partidos políticos con una marcada militancia activa y pasiva de jóvenes. Ciudadanos y Podemos son ejemplos de este nuevo patrón político-partidario. Sería interesante replicar en la actualidad este estudio para detectar cómo, a día de hoy, la religiosidad se está vinculando con los niveles poseídos de competencias cívicas.

En tercer lugar, una explicación de estos hallazgos podría venir dada por el carácter marcadamente secularizado de la sociedad española en contraste con lo sucedido en los entornos anglosajones que se toman como referencia en este tipo de estudios. La secularización ha venido de la mano de la individualización de las opciones de vida y ambos fenómenos no sólo afectan a los sujetos no religiosos sino que también penetran en los modos de pensar y actuar de las personas con vocación espiritual. Unos y otros pueden verse limitados por su sujeción a estas lógicas en su deseo de actuación en ámbitos comunitarios y/o políticos. La vivencia y profundidad espiritual, en escenarios como los descritos, podría encontrarse escindida de la necesidad o deseo de acción en el espacio público.

Naturalmente, esta presentación de los resultados cuenta con limitaciones. Los mismos deben seguir siendo trabajados para ver cómo la religiosidad puede, en su interacción con otras variables, estar propiciando diferentes niveles de competencias cívicas (Biderbost, 2014; Just, Sandovici y Listhaug, 2013). Una primera aproximación pendiente es la que intentaría observar cómo el background democrático/autoritario de las sociedades de origen podría estar influyendo en materia de integración política en el país receptor. Sujetos 
acostumbrados socialmente a prácticas democráticas podrían ver estimulado su perfil cívico en las sociedades de recepción.

Una segunda aproximación por explorar es la que se vincula a la religión concreta que profesan los sujetos con vocación espiritual. A ella, podría adicionarse otro factor que refiera a la región del mundo de la que proceden los inmigrantes. Ambos fungen como proxys del entorno cultural de origen. La exploración de datos inspirada en esta mirada vendría a dar respuesta empírica a algunos de los supuestos expuestos por Huntington (2000) en su ya clásica contribución.

Una tercera aproximación por ejecutar es la que incorpora dimensiones ideológicas. La ubicación de los sujetos en el continuum ideológico izquierdaderecha podría encerrar, en su cruce con religiosidad, explicaciones interesantes vinculadas al perfil cívico de los inmigrantes en sociedades de acogida. Al respecto, existe evidencia empírica que respalda abiertamente el hecho de que la militancia política puede ser producto de una militancia socio-religiosa tanto progresista como conservadora (Guth y Green, 1990).

\section{CONCLUSIONES}

En entornos anglosajones, la religiosidad parece incidir, con independencia del credo que se profese, en la posesión de competencias cívicas. En el caso de la población de origen inmigrante, adulta o adolescente, estas habilidades son un indicador de su integración política en las sociedades de acogida. La práctica religiosa ofrece, en estos contextos, una catapulta para la acción política.

Mientras menos distancia exista entre nativos e inmigrantes en niveles de competencias cívicas, se desprenden diferentes beneficios. En primer lugar, se afirma que los recién llegados se asemejan en sus patrones cívicos a los autóctonos y ello habla de una normalización bidireccional: por un lado, el sistema político los ha acogido de manera no diferenciada y, por el otro, los nuevos ciudadanos se relacionan confiadamente con el entramado político de la sociedad de acogida (partidos políticos, parlamentos estatales, autonómicos y locales y administración pública). En segundo lugar, brechas menores son sugerentes de que se está en frente de altos ratios de calidad de la democracia (Levine y Molina, 2011). Los regímenes democráticos, una vez consolidados son medidos en su calidad y ésta toma como indicadores cuánto los individuos participan, escogen y controlan a las autoridades públicas. Cuando un grupo social presenta valores que se apartan del estándar o media, ello podría estar delatando la presencia de bolsas de potencial o actual marginación cívica que, sostenidas en el tiempo, podrían hacer mella en la estabilidad del sistema. 
La investigación reproducida en estas páginas delata que diferentes variables contribuyen a la integración política de los inmigrantes adolescentes en España. El tiempo de residencia en la sociedad de acogida y los agentes de socialización vinculados al entorno receptor (grupo de pares y escuela) desempeñan un rol estelar al respecto. La empatía y disposición a ayudar (actitud pro-sociales) actúan también como factor catalizador. A pesar de las previsiones teóricas, la religiosidad no cumple esa tarea. Diferentes motivos pueden atentar contra ello. La novel tradición inmigratoria en España, la bonanza económica vivida en tiempos de la recolección de los datos y la marcada secularización social pueden encontrarse entre los mismos. La reproducción, a día de hoy, de una muestra semejante podría arrojar luz sobre cómo la práctica religiosa, de manera solitaria o en interacción con las variables reseñadas, puede influir en el protagonismo político de los jóvenes extranjeros.

\section{REFERENCIAS BIBLIOGRÁFICAS}

Bermúdez, A. "La integración política de los migrantes latinoamericanos en Andalucía, Madrid y Cataluña". Trabajo presentado en las Actas del I Congreso Internacional sobre Migraciones en Andalucía, Universidad de Granada, España, February 16-18, 2011.

Bevelander, P. y Pendakur, R. "Social capital and voting participation of immigrants and minorities in Canada". Ethnic and Racial Studies 32 (2009): 1406-1430.

Biderbost, P. "La cultura política de los jóvenes inmigrantes latinoamericanos en España. El desarrollo cívico como indicador de su integración política". En Inmigración latinoamericana en España. El estado de la investigación, editado por Ayuso, A. y Pinyol, G., 167-215. Barcelona: Fundació CIDOB, Edicions Bellatera y Fundación Carolina, 2010.

- . "The political integration of the adolescents. The civic competencies of the migrants in the Spanish secondary school". PhD diss., Universidad de Salamanca, 2014.

Biderbost, P., Bolzman, C. y Boscán G. "Patterns of political transnationalism in a non-traditional diaspora. The case of Swiss citizens in Latin America". En The Routledge Companion to MIgration, Communication and Politics, editado por. S.M. Croucher, J. Caetano and E.A. Campbell, 245-265. London: Routledge, 2019.

Biderbost, P., y Boscán, G. "The use of canonical correlation analysis and heliograph for explaining patterns of political integration among migrants in 
host societies". SAGE Research Methods Cases (2019). doi:10.4135/97815 26468949

Bloemraad, I. Becoming a citizen: Incorporating immigrants and refugees in the United States and Canada. Berkeley: University of California Press, 2006.

Brady, H. E., Verba, S. y Schlozman, K. L. "Beyond SES: A resource model of political participation". American Political Science Review 89 (1995): 271 294.

Clark, M. "Canonical Correlation with SPSS.", 2006, http://www.unt.edu/ben chmarks/archives/2006/january06/rss.htm

Dana, K., Barreto, M. A., \& Oskooii, K. A. "Mosques as American institutions: Mosque attendance, religiosity and integration into the political system among American Muslims". Religions 2 (2011): 504-524.

Dahl, R. J. Who Governs? Democracy and Power in an American City. New Haven: Yale University Press, 1961.

Degani, A., Shafto, M. y Olson, L. "Canonical correlation analysis: Use of composite heliographs for representing multiple patterns". En Diagrammatic Representation and Inference, editado por Barker-Plummer, D., Cox, R. y Swoboda, N, 93-97. Berlín: Springer, 2006.

Djupe, P. A. y Grant, J. T. "Religious institutions and political participation in America". Journal for the Scientific Study of Religion 40 (2001): 303-314.

Dudley, R. L. y Gitelson, A. R. "Political literacy, civic education, and civic engagement: A return to political socialization?". Applied Developmental Science 6 (2002): 175-182.

Easton, D. y Dennis, J. "The child's acquisition of regime norms: Political efficacy". The American Political Science Review 61 (1967): 25-38.

Eisenstein, M. A. "Rethinking the relationship between religion and political tolerance in the US". Political Behavior 28 (2006): 327-348.

Glazer, N. "The integration of American immigrants". Law and Contemporary Problems 21 (1956): 256-269.

Glatfelter, A. "Canonical correlation", 2009, http://academic.csuohio.edu/ neuendorf ka/COM53109/CC.pdf

González-Ferrer, A. "The electoral participation of naturalized immigrants in ten European cities". En Social Capital, Political Participation and Migration in Europe: Making Multicultural Democracy Work?, editado por Morales, L. y Giugni, M. G., 245-265. Basingstoke: Palgrave, 2011.

Guth, J., \& Green, J. C. "Politics in a new key: religiosity and participation among political activists". Western Political Quarterly 43 (1990): 153-179.

Hair, J. F., Anderson, R. E., Tatham, R. L. y Black, W. C. Multivariate data analysis. Madrid: Macmillan, 2007. 
Hammar, T. "Comparing European and North American International Migration”. International Migration Review 23 (1989): 631-637.

Huntington, S. P. “The clash of civilizations?". En Culture and Politics, editado por Huntington, S. P, 99-118. New York: Palgrave Macmillan, 2000.

Jacobs, D. y Tillie, J. "Introduction: social capital and political integration of migrants". Journal of Ethnic and Migration Studies 30 (2004): 419-427.

Jamal, A. "The political participation and engagement of Muslim Americans: Mosque involvement and group consciousness". American Politics Research 33 (2005): 521-544.

Jones-Correa, M. A. y Leal, D. L. "Political participation: Does religion matter?" Political Research Quarterly 54 (2001): 751-770.

Kelly, N. J. y Morgan, J. "Religion and Latino partisanship in the United States". Political Research Quarterly 58 (2005): 87-95.

Langton, K. P. y Jennings, M. K. "Political socialization and the high school civics curriculum in the United States". The American Political Science Review 62 (1968): 852-867.

Leighley, J. E. y Vedlitz, A. "Race, ethnicity, and political participation: Competing models and contrasting explanations". Journal of Politics 61 (1999): 1092-1114.

Levine, D.H. y Molina, J.E. The Quality of Democracy in Latin America Londres: Lynne Rienner Publishers, 2011.

McAndrew, S., \& Voas, D. "Immigrant generation, religiosity and civic engagement in Britain". Ethnic and Racial Studies 37 (2014): 99-119.

Metz, E. C. y Youniss, J. "Longitudinal gains in civic development through school-based required service". Political Psychology 26 (2005): 413-438.

Miller, A. H. y Wattenberg, M. P. "Politics from the Pulpit: Religiosity and the 1980 Elections". Public Opinion Quarterly 48 (1984): 301-317

Morales, L. "'Conceptualizing and Measuring Migrants' Political Inclusion": En Social Capital, Political Participation and Migration in Europe: Making Multicultural Democracy Work?, editado por Morales, L. y Giugni, M. G., 19-42. Basingstoke: Palgrave, 2011.

Morales, L. y Giugni, M. G. (Eds.). Social Capital, Political Participation and Migration in Europe: Making Multicultural Democracy Work? Basingstoke: Palgrave, 2011.

Morales, L., Anduiza, E., Rodríguez, E. y San Martín, J. “Capital social, pautas identitarias y actitudes hacia "los otros": la incorporación cívica de la población de origen inmigrante en Barcelona y Madrid". Panorama Social (2008): 8.

Morales, L. y Morariu, M. "Is Home a distraction? The role of migrants' transnational practices in their political integration into receiving-country 
politics". En Social Capital, Political Participation and Migration in Europe: Making Multicultural Democracy Work?, editado por Morales, L. y Giugni, M. G, 140-171. Basingstoke: Palgrave, 2011.

Niemi, R. G. y Chapman, C. The Civic Development of 9th Through 12th Grade Students in the United States: 1996. Washington: National Center for Education Statistics, 1998.

Niemi, R. G. y Sobieszek, B. I. "Political socialization”. Annual Review of Sociology 3 (1977): 209-233.

O'Neill, B., Gidengil, E. y Young, L. "The Political Integration of Immigrant and Visible Minority Women". Canadian Political Science Review 6 (2012): 185-196.

Portes, A., Escobar, C. y Arana, R. "Bridging the gap: transnational and ethnic organizations in the political incorporation of immigrants in the United States". Ethnic and Racial Studies 31 (2008): 1056-1090.

Rex, J. y Singh, G. "Pluralism and Multiculturalism in Colonial and Post-Colonial Society - Thematic Introduction". International Journal of Multicultural Societies 5 (2003): 106-118.

Ryan, A. M. "The peer group as a context for the development of young adolescent motivation and achievement". Child Development 72 (2001): 1135 1150 .

Torney-Purta, J., Barber, C. y Wilkenfeld, B. "Latino Adolescents' civic development in the United States: research results from the IEA Civic Education Study". Journal of Youth and Adolescence 36 (2007): 111-125.

Turska-Kawa, A. "Centrality of religiosity versus civic involvement. The case of Poland". Communist and Post-Communist Studies 51 (2018): 39-48.

White, S., Nevitte, N., Blais, A., Gidengil, E. y Fournier, P. "The Political Resocialization of Immigrants: Resistance or Lifelong Learning?”. Political Research Quarterly 61 (2008): 268-281.

Yates, M. y Youniss, J. Roots of Civic Identity: International Perspectives on Community Service and Activism in Youth. Nueva York: Cambridge University Press, 1999.

\begin{tabular}{|r|r|}
\hline Guillermo Boscán Carrasquero & Pablo Nicolás Biderbost \\
Facultad de Comunicación & Dep. de Relaciones Internacionales \\
Universidad Pontificia de Salamanca & Universidad Pontificia Comillas \\
Henry Collet, 90-98 & Universidad Pontificia Comillas, 3-5 \\
37007, Salamanca (España) & 28049, Madrid (España) \\
https://orcid.org/0000-0002-4199-2160 & http://orcid.org/0000-0002-4086-3658 \\
\hline
\end{tabular}


